IIUC STUDIES

ISSN 1813-7733

Vol.- 7, December 2010

(Published in December 2011) (p 107-116)

\title{
Design, Implementation and Performance Analysis of a Low-cost Optical Tachometer
}

\author{
A. S. M. Bakibillah* \\ Muhammad Athar Uddin ${ }^{* *}$ \\ Shah Ahsanul Haque ${ }^{* * *}$
}

\begin{abstract}
Electrical and mechanical machineries are used in industrial and domestic applications. Measurement of speed of revolving machineries is necessary for their proper functioning and controlling. Tachometer is an instrument which is used to measure the speed of revolving shaft, gear and pulley. This paper describes the basic construction of a low cost optical tachometer and analyzes its performance. The basic tachometer circuit consists of two stages. In the first stage monostable wired around IC NE555 is used, and in the second stage a digital counter based 4-digit counter IC 74C926 is used for the construction of the tachometer. A $5 \mathrm{~V}$ regulated power supply circuit and an infrared light source circuit are also used. The instrument can measure speed upto 9999 RPM. This speed measurement instrument performs well in terms of accuracy, and can be very useful due to its simplicity and low cost.
\end{abstract}

Keywords: Tachometer, monostable operation, digital counter, infrared light source.

\section{INTRODUCTION}

A tachometer is a fairly common instrument designed to measure the rotation speed of an object or substance. The term comes from Greek tachos, meaning speed, and metron, meaning to measure. The

\footnotetext{
* $\quad$ Lecturer, Dept. of Electrical \& Electronic Engineering, IIUC, Dhaka Campus.

** Assistant Professor, Dept. of Electrical \& Electronic Engineering, IIUC, Dhaka Campus.

*** Lecturer, Dept. of Electrical \& Electronic Engineering, IIUC, Dhaka Campus.
} 
tachometer is laid out traditionally as a calibrated analog dial, with a pointer indicating the current reading and markings indicating safe and dangerous ranges of speeds. A tachometer measures the speed in revolutions per minute (RPM) at which a mechanical device is rotating. The traditional tachometer requires physical contact with the device being measured. In certain situations, this is not feasible for technical or safety reasons. So to improve the safety of operation, here an optical tachometer is developed which is also cost effective.

The proposed optical tachometer can be used to measure speed from a distance. The tachometer works by pulsing tight beam of light against a reflective spot of the rotating element. It measures the rate at which the light beam is reflected, and displays the speed in RPM in a 4-digit display. It can be used as a permanent or integrated part of the system, or as a handheld device for occasional spot measurements.

This paper is organized as follows. An overview of the setup of the proposed tachometer is given in Section 2. The Infrared light source circuit and IR receiver module are described in Section 3. The operation of monostable multivibrator of 555 timer is discussed in Section 4. Digital counter and display circuit are discussed in Section 5. Section 6 covers the experimental results and performance analysis and section 7 points out the conclusion inferred from this work.

\section{OVERVIEW OF THE TACHOMETER}

The block diagram of the optical tachometer circuit is given in Figure 1. The dc power supply unit supplies a constant 5 volt to infrared light source, infrared light receiver monostable multivibrator and counter circuit. Light is incident on the rotating object from an infrared light source. The reflected light from the object is received by the infrared light detector. The detector outputs a modulated voltage signal with frequency same as that of the rotating substance. The monostable multivibrator converts the incoming signal into pulses, which is counted and displayed by the counter and the display respectively.

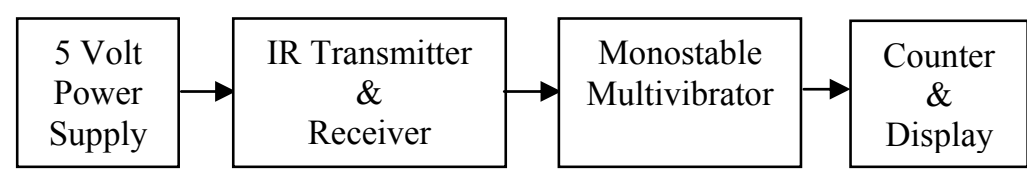

Figure 1: Block diagram of an optical tachometer. 


\section{IR LIGHT SOURCE CIRCUIT AND IR RECEIVER MODULE}

An infrared light emitting diode is used as a source of light which falls on the strip of rotating object, as shown in Figure 2. Infrared light is invisible with wavelength of $0.7-2 \mu \mathrm{m}$. The IR (infrared) light is received by the reflection of light with the help of infrared light source circuit. The reflected light from a rotating body falls on the junction of the sensor module to activate and deactivate it alternately. The available range of different carrier frequencies is given in Table 1.

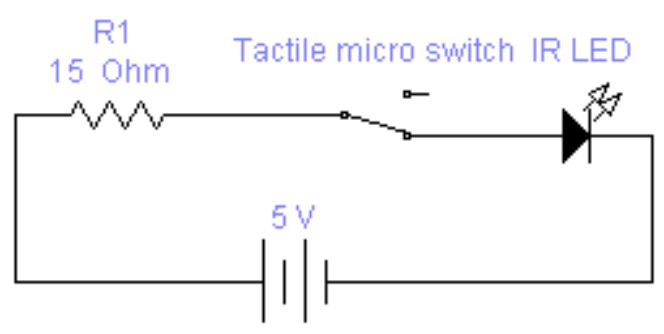

Figure 2: IR light source circuit.

The TSOP 17XX series, shown in Figure 3, are miniaturized receivers for infrared remote control systems. PIN diode and preamplifier are assembled on lead frame in an epoxy package. The IC is designed as an IR filter. The demodulated output signal can directly be decoded by a microprocessor. The important features of the TSOP 17XX series are as follows:

(I) Photo detector and preamplifier in one package, (II) Internal filter or PCM frequency,

(III) Low power consumption, (IV) Light immunity against ambient light. 
Table-1: IR light source ICs with their corresponding carrier frequencies.

\begin{tabular}{|l|c|}
\hline IC no. & $f_{o}$ (in \\
\hline TSOP 1730 & 30 \\
\hline TSOP 1733 & 33 \\
\hline TSOP 1736 & 36 \\
\hline TSOP 1737 & 36.7 \\
\hline TSOP 1738 & 38 \\
\hline TSOP 1740 & 40 \\
\hline TSOP 1756 & 56 \\
\hline
\end{tabular}

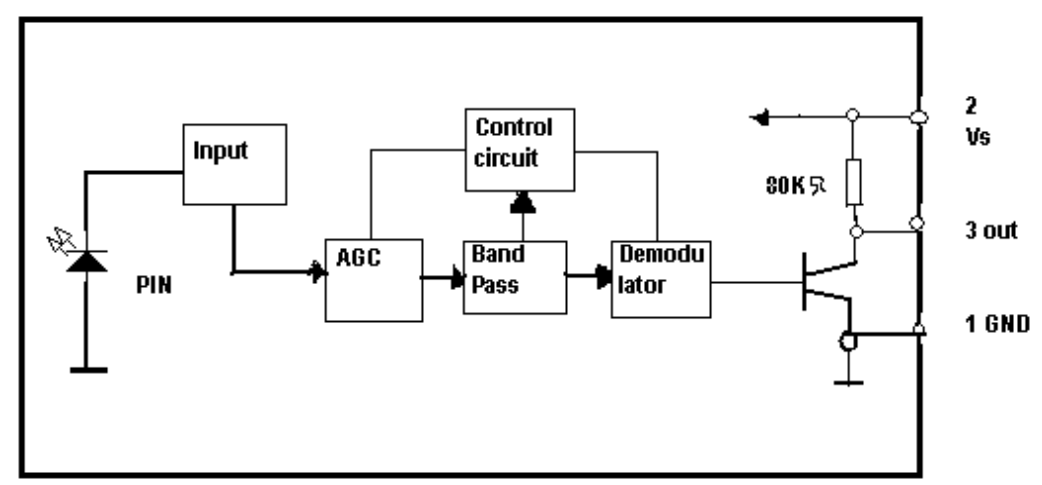

Figure 3: Block diagram of the TSOP $17 X X$ series.

\section{MONOSTABLE MULTIVIBRATOR OPERATION OF 555 TIMER}

An electronic circuit which generates square waves or other nonsinusoidal ones, such as rectangular and sawtooth waves, is known as a multivibrator $[1,2]$. The name multivibrator is derived from the fact that a square wave (and other non-sinusoidal waves) actually consists of a large number of sinusoids of different frequencies. Monostable or one shot multivibrator is a pulse generating circuit in which the duration of pulse is determined by the RC network connected externally to the 555 timer, as shown in Figure 4. 


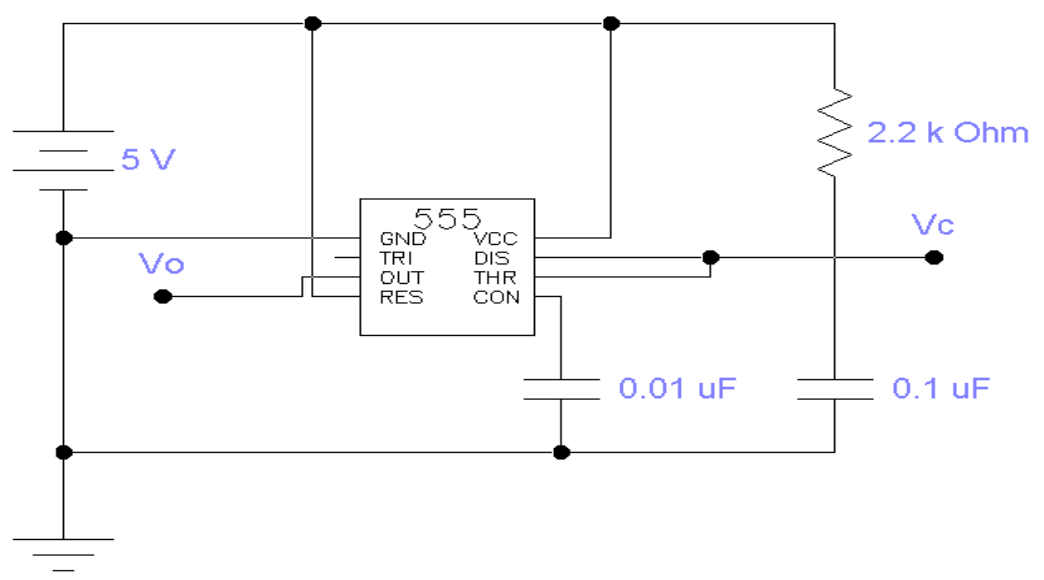

Figure 4: Monostable operation of 555 timer.

A multivibrator is in monostable mode when one transistor is always at ON state and the other is at OFF state. In other words, if one transistor is conducting and the other is not, the circuit will operate in monostable mode. In a stable or stand-by state, the output of the circuit is approximately zero or at logic low level. When an external trigger pulse is applied, the output is forced to go high $\left(\approx \mathrm{V}_{\mathrm{cc}}\right)$. The time the output remains high is determined by the external RC network connected to the timer. At the end of the timing interval, the output automatically reverts back to its logic low stable state. The output stays low until the trigger pulse is applied again $[1,2]$. The monostable circuit has only one stable state (output low), hence the name monostable. The output is remaining high for $\mathrm{t} 1$ second.

$$
\begin{aligned}
& \mathrm{t}_{1} \text { (seconds) }=1.1 \times \mathrm{R}_{\mathrm{a}} \times \mathrm{C} / 1000 \text {; where, } \\
& \mathrm{R}_{\mathrm{a}}=2.2 \mathrm{~K} \Omega \text { and } \mathrm{C}=0.1 \mu \mathrm{F} \text {; so } \mathrm{t}_{1}=242 \mu \mathrm{S} .
\end{aligned}
$$

\section{DIGITAL COUNTER AND DISPLAY CIRCUIT}

Counter is a register that is capable of counting the number of clock pulses that have arrived at its clock input. The count is displayed in suitable form with display. A register is a group of memory elements that work together as a unit. In this work counter IC MM74C926 and 7-segment display circuit are used. IC MM74C926 is a CMOS counter consisting of a 4-digit counter, an internal output latch, NPN output sourcing drivers for a 7-segment display, and an internal 
multiplexing circuitry with four multiplexing outputs [5]. The multiplexing circuit has its own free-running oscillator and requires no external clock. The block diagram of IC MM74C926 is given in Figure 5.

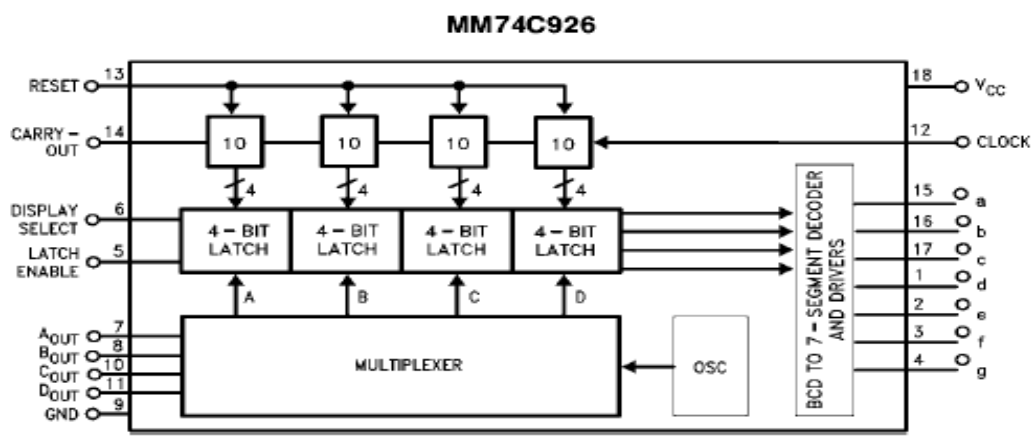

Figure 5: Block diagram of IC MM74C926 [5].

IC 74C926 is basically a 4-digit counter module, which can count from 1 to maximum possible value of 9999. It triggers on negative edge clock pulses. The input pulses are applied to clock pin 12 of 74C926. Input to Latch Enable and Display Select pin are kept high so that the number in the counter is displayed. The segment output driver and input protection circuit are shown in figures 6 and 7, respectively [5]. When these pins are low, the number in the latch will be displayed. On receipt of every pulse count of IC, digits are incremented by one which is displayed on display $[3,4]$. The input waveform and the switching time waveform of counter circuit are given in figures 8 and 9, respectively. IC 74C926 has a multiplexing circuit with four outputs. Output of the multiplexer is connected to 4bit latch whose output is a binary coded decimal (BCD) number. In a $\mathrm{BCD}$ number, each decimal number is represented by 4-bit. Outputs from latch are fed to BCD to 7-segment display driver. 7-segment configuration is used to display decimal characters 0 through 9. A $\mathrm{BCD}$ to 7-segment driver takes 4-bit BCD input and provides the outputs that will pass current through appropriate segments to display the decimal digit. 7-segment LED display 1050CHRI is used in common cathode connection as the display. In common cathode 7 segment LED display, cathodes of all segments are grouped together and connected to ground. Since IC 74C926 is a CMOS device, it cannot be used to drive common cathode display directly. Consequently, a transistor is used as an interface circuit between the decoder chip and the common cathode display. The chip 74C926 pulls 
its carry output (pin 14) high when counter reaches 6000. Carry is not used in this circuit. A reset switch is connected between pin 13 and ground, which can be reset as need arises.
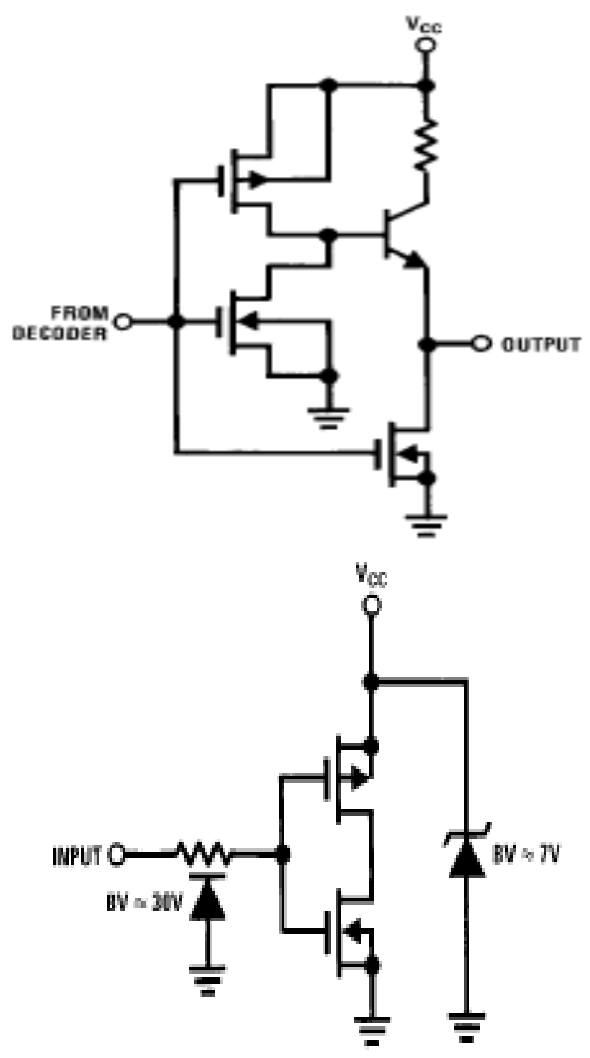

Figure 6: Segment output driver Figure 7: Input protection circuit

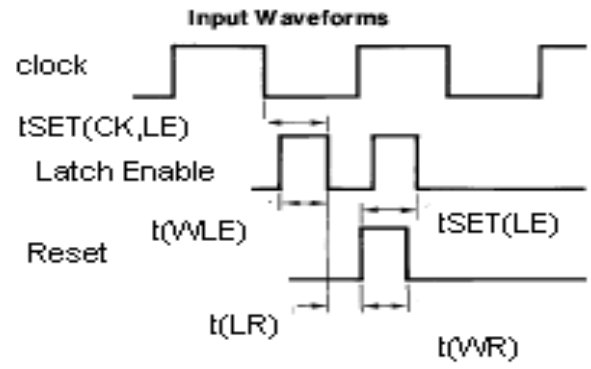

Figure 8: Input waveform of counter circuit. 


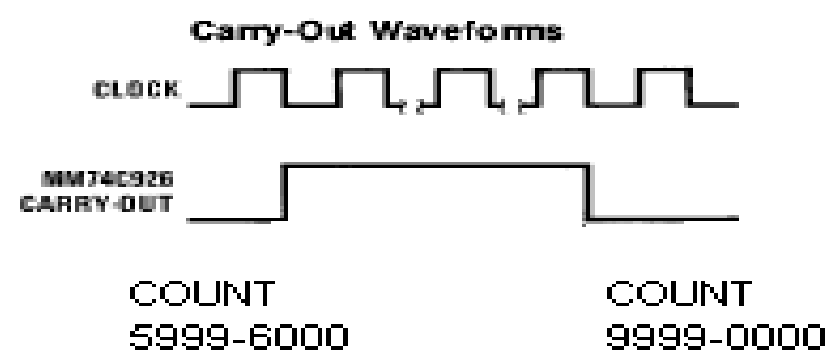

Figure 9: Switching time waveform.

\section{EXPERIMENTAL RESULTS}

To justify the performance of the proposed tachometer, motors with different rated RPM were run, and the proposed tachometer along with a conventional one was used to measure the RPM. The performance is given in Table 2. The performance of the optical tachometer is found to be good enough for laboratory, industry and many other applications where speed measurement is a necessity. Table 3 shows the relative comparison between the proposed optical tachometer and conventional optical tachometer.

Table 2: Performance analysis between conventional and proposed optical tachometer

\begin{tabular}{|c|c|c|c|}
\hline $\begin{array}{c}\text { Observation } \\
\text { No. }\end{array}$ & $\begin{array}{c}\text { Speed } \\
\text { measurement } \\
\text { using } \\
\text { conventional } \\
\text { optical } \\
\text { tachometer } \\
\text { (RPM) }\end{array}$ & $\begin{array}{c}\text { Speed } \\
\text { measurement } \\
\text { using proposed } \\
\text { tachometer } \\
\text { (RPM) }\end{array}$ & $\begin{array}{c}\text { \% of deviation } \\
\text { from the speed } \\
\text { measured by } \\
\text { conventional } \\
\text { tachometer }\end{array}$ \\
\hline 1 & 2950 & 3180 & 7.80 \\
\hline 2 & 2830 & 2960 & 4.60 \\
\hline 3 & 1500 & 1600 & 6.66 \\
\hline
\end{tabular}


Table 3: Comparison between conventional and proposed optical tachometer

\begin{tabular}{|c|c|c|c|c|}
\hline $\begin{array}{c}\text { Type of } \\
\text { Tachometer }\end{array}$ & $\begin{array}{l}\text { Range } \\
\text { of } \\
\text { RPM }\end{array}$ & $\begin{array}{c}\text { Basic Circuits } \\
\text { Used }\end{array}$ & $\begin{array}{c}\text { Operating } \\
\text { Temperatur } \\
\text { e / Amp. } \\
\text { flow }\end{array}$ & $\begin{array}{l}\text { Cost per Meter } \\
\text { (Approximately) }\end{array}$ \\
\hline $\begin{array}{c}\text { Proposed } \\
\text { Optical } \\
\text { Tachometer }\end{array}$ & $\begin{array}{c}1 \text { to } \\
9999\end{array}$ & $\begin{array}{c}\text { (1) Monostable } \\
\text { pulse generator } \\
\text { (IC NE555) } \\
\text { (2) } \\
\text { Digital counter } \\
\text { and Display } \\
\text { circuit (IC } \\
\text { MM74C926) } \\
\text { (3) } 7 \text { Segment } \\
\text { display }\end{array}$ & $\begin{array}{c}10^{\circ} \mathrm{C}-45^{\circ} \mathrm{C} / \\
200 \mathrm{~mA}\end{array}$ & TK. 1,500 \\
\hline $\begin{array}{l}\text { Convention } \\
\text { al Optical } \\
\text { Tachometer }\end{array}$ & $\begin{array}{l}0.1 \text { to } \\
99999\end{array}$ & $\begin{array}{c}\text { (1) Micro } \\
\text { Computer LSI } \\
\text { Circuit } \\
(2) \\
\text { LCD Display }\end{array}$ & $\begin{array}{c}0^{\circ} \mathrm{C}-55^{\circ} \mathrm{C} / \\
150 \mathrm{~mA}\end{array}$ & TK. 10,000 \\
\hline
\end{tabular}

\section{DISCUSSION}

Advantages of conventional tachometer over proposed tachometer:

(I) Range of RPM is higher (II) Power consumption is lower (III) Wide temperature range

\section{Advantages of proposed tachometer over conventional tachometer: \\ (I) Very simple circuit diagram and construction (II) Low manufacturing cost.}

Segment resistors are desirable in the circuit to minimize power dissipation and chip heating. When using driver with $5 \mathrm{~V}$ supply at room temperature, the display can be driven without segment resistors to full illumination. In this mode care should be taken to prevent overheating that the supply voltage and the ambient temperature are not too high.

The proposed tachometer finds its applicability in many fields, such as fast response over speed shut down, petrochemical production applications, pump or generator applications, low speed switching, 
machine control, turbine speed control, printing industry, mining applications, generator sets etc. It can be used to count the number of objects transferred by a conveyer belt.

\section{CONCLUSION}

An optical tachometer is proposed in this work. It can be operated with a supply of $3-15 \mathrm{~V}$, which is low enough and suits to most of the applications. Though in our proposed tachometer the range of maximum measured speed is lower than the that of conventional tachometer and current drawn (power consumption) by the proposed tachometer is a little bit higher but due to its simplicity and low manufacturing cost it will be better for industrial and laboratory application.

\section{REFERENCES:}

RAMAKANT A. GAYAKWAD, (1999). “Op-Amps and Linear Integrated Circuits", $4^{\text {th }}$ ed. 4, Prentice Hall.

ROBERT F. COUGHLIN \& FREDERICK F. DRISCOLL, (2000). "Operational Amplifiers and Linear Integrated Circuits", $6^{\text {th }}$ ed., Prentice Hall.

RONALD J. TOCCI; NEAL S. WIDMER \& GREGORY L. MOSS, (2006). "Digital Systems: Principles and Applications", $10^{\text {th }}$ ed., Prentice Hall.

ALBERT P. MALVINO \& JERALD A. BROWN, (1992). "Digital Computer Electronics", 3th ed., Career Education.

http://www.datasheet.com

http://www.vishay.com 